\title{
Influence of flood regime on riparian vegetation dynamics in rivers with alternate bars
}

\author{
Camille Jourdain ${ }^{1, *}$, Nicolas Claude $^{2}$, Germain Antoine ${ }^{1,2}$, Pablo Tassi ${ }^{1,2}$, and Florian \\ Cordier $^{1,2}$ \\ ${ }^{1}$ Laboratoire d'Hydraulique Saint Venant - École des Ponts Paris Tech, Électricité de France R\&D, \\ CEREMA - 6 quai Watier, BP49, 78400 Chatou, France \\ ${ }^{2}$ Laboratoire National d'Hydraulique et d'Environnement (LNHE) - Électricité de France R\&D - 6 quai \\ Watier, 78400 Chatou, France
}

\begin{abstract}
Throughout the 20th century, many rivers worldwide have undergone important riparian vegetation encroachment, which can be problematic in terms of flood risks and biodiversity. Nowadays, controlled floods is often considered as a management option in anthropized rivers, with the aim of limiting vegetation encroachment within river channels, as well as maintaining a diverse habitat by reactivating natural channel dynamics. In this context, this study aims at investigating the influence of different flood regimes on river bar vegetation development and dynamics, focussing on alternate bar systems which are typically found in embanked streams. This question has been addressed through two-dimensional bio-morphodynamic modeling of a simplified gravel bed river reach. Four hydrological scenarios with different flood peak discharges have been run for 50 years. For all scenarios, a steady increase in vegetation cover strongly impacts the evolution of bar morphology, until a relatively stable equilibrium is reached after one to three decades. Numerical results suggest that vegetation development on bars is associated to an increase in bar wavelength and a decrease in bar width. Higher peak flood discharges lead to narrower and longer bars, and a longer adjustment duration. When vegetation cover is fully developed, interannual flood variability seems crucial to maintain bedform and vegetation turnover.
\end{abstract}

\section{Introduction}

Many rivers worldwide have recently narrowed and stabilized, so that mature vegetation has been able to establish lastingly on fluvial bedforms $[1,2]$. These alterations can be triggered by human activity in river basins, such as damming or land use changes [3]. They are usually associated to a loss of habitat diversity: reduced channel activity hampers the mobilization and renewal of fluvial bars and islands during floods, which is necessary for different habitats with multiple vegetation ages to coexist in river channels and floodplains [4]. Vegetation encroachment on fluvial macroforms can also increase flood risks since the presence of vegetation increases roughness, thereby decreasing flow velocities and increasing water levels for given discharges. This phenomenon can be a particularly serious concern in embanked

\footnotetext{
*e-mail: cam.jourdain@gmail.com
} 
reaches with highly anthropized floodplains and no possibility for flood expansion outside the dikes. Figure 1 presents an example of an embanked reach with alternate bars, which has recently undergone important vegetation development: while bars were free of vegetation in 1956 (Figure 1.A), a fully developed riparian forest has grown on the bars by 2016 (Figure 1.A). Environmental flows is a management option often considered in anthropized rivers, with the aim of limiting vegetation encroachment within river channels and of maintaining a diverse habitat by reactivating natural channel dynamics $[5,6]$.

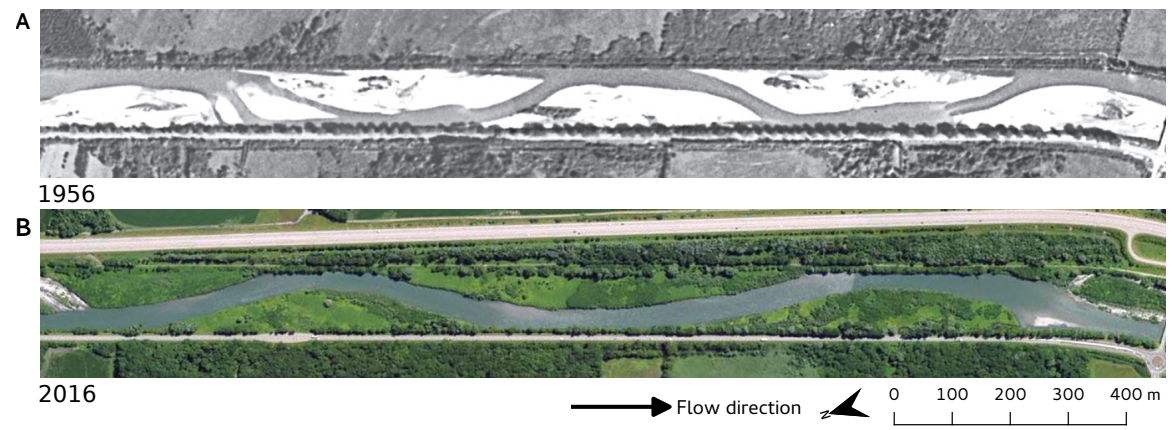

Figure 1. Alternate bars of the Isère River near Aiton, France (LA 93 coordinates : 955240, 6504520), before and after vegetation development, A. in 1956, and B. in 2016

In this context, this study aims at investigating the influence of different flood regimes on the dynamics of vegetation developing on river bars, focussing on alternate bar systems which are typically found in embanked streams. Alternate bars have been extensively studied analytically $[7,8]$, experimentally $[9,10]$, numerically $[11]$ and more recently in field settings $[12,13]$. Even though a number of investigations have outlined the importance vegetation can have on bar dynamics, only few studies have addressed this issue [14, 15].

In this work, numerical modeling experiments have been performed in order to document the influence of flood regime on vegetation development on bars, as well as the concomittant evolution of bar dimensions and morphodynamics. Current two-dimensional (2D) morphodynamic models have been shown effective to simulate alternate bar dynamics without vegetation $[10,11]$. Moreover, as interactions between riparian vegetation and channel dynamics are better understood and quantified $[16,17]$, the representation of riparian vegetation in 2D morphodynamic models has shown satisfactory results at reproducing key morhodynamic behaviours, and notably the transition from braiding to meandering channel patterns [18-20]. A recent modeling study has focussed on the conditions for which vegetation develops on alternate bars, demonstrating a threshold behaviour [14]. Here, we have investigated the evolution and dynamics of alternate bars with vegetation as a function of flood regime.

\section{Materials and methods}

A dynamic vegetation module has been coupled internally to a morphodynamic model, based on the life cycle of one type of vegetation representative of salicaceous species.

\subsection{Bio-morphodynamic modeling}

\subsubsection{Morphodynamic modeling}

Hydrodynamics and morphodynamics are computed with the open source Telemac-Mascaret modeling system (http://www.opentelemac.org/). The hydrodynamics are computed by 
solving the depth-averaged shallow-water equations, with a correction for secondary currents [21]. Sediment fluxes are computed using the Meyer-Peter and Müller formula for a uniform grain size [22], and bed elevation is adjusted by solving the Exner mass balance equation [23]. Deviation of sediment fluxes due to secondary currents and gravity effects are also considered [21]. Bank erosion is represented with a simple gravity-based model, keeping a constant angle of repose [24]. This model has been shown to reproduce well the temporal evolution of river bars in comparison to experimental results [11].

\subsubsection{Vegetation dynamics}

The influence of vegetation on hydraulics is described through a drag force exerted on the flow field, and added to the momentum conservation equation $[25,26]$ :

$$
\overrightarrow{F_{d}}=-\frac{1}{2} C_{d} \rho \alpha_{v} A \min \left(h_{v}, h\right)\left|\vec{U}_{v}\right| \vec{U}_{v}
$$

where $C_{d}$ is the drag coefficient, $\rho$ is water density $\left(\mathrm{kg} / \mathrm{m}^{3}\right), \alpha_{v}$ is a shape factor equals to 1 for a rigid cylinder, $A=m * D$ is the projected area of stems in the flow direction $\left(\mathrm{m}^{2}\right), m$ being the number of stems per $\mathrm{m}^{2}$, and $D$ the stem diameter $(\mathrm{m}), h_{v}$ and $h$ are respectively the plant height and the water depth $(\mathrm{m})$, and $\vec{U}_{v}$ is the vector of flow velocity acting on vegetation $(\mathrm{m} / \mathrm{s})$. If $h_{v}>h$ (emerged vegetation), $\vec{U}_{v}=\vec{U}$, the depth averaged velocity. If $h_{v}<h$ (submerged vegetation), the formulation of Stone and Sheng [25] is used. Vegetation is represented as rigid cylinders. This formulation has been validated against experimental results [26]. In this model, vegetation influences sediment transport indirectly by directly impacting the flow field, which retroactively modifies sediment transport.

Recruitment stage (germination and seedling dispersal) and later development stages are simulated using different processes. Indeed, vegetation is particularly vulnerable during its first development stages and has very little impact on the flow field. In contrast, older vegetation is less vulnerable and has a great influence on channel dynamics [16].

Conditions for seedling recruitment are assessed from May $1^{\text {st }}$ to September $1^{\text {st }}$, which constitutes vegetation growing season in temperate areas of the Northern Hemisphere. Seeds are dispersed in May and June; they are deposited and can germinate on bare, moist surfaces, that is between minimum and maximum water elevation recorded during this period. July and August are crucial to seedling survival: seedling mortality can be caused by prolonged inundation, desiccation, burial, or uprooting $[27,28]$. Where germination has been possible and no seedling mortality has occured, vegetation age is set to 1 on September $1^{\text {st }}$. Beforehand, seedlings have no impact on the flow field.

After this sensitive stage, vegetation characteristics are updated every year. Stem density $m$ is held constant, while vegetation height $h_{v}$ and diameter $D$ are computed as follows [20]:

$$
G= \begin{cases}G_{i n} & \text { for Age }=1 \text { year } \\ F_{v} \cdot \log (\text { Age }) & \text { for Age }>1 \text { year } \\ F_{v} \cdot \log (10) & \text { for Age }>10 \text { years }\end{cases}
$$

where $G$ is variable size, and $F_{v}$ is a growth parameter which is different for each variable and species specific. Mortality of vegetation of 1 year old and more occurs through processes of burial, which occurs if deposition exceeds vegetation height [29], or uprooting, which occurs if erosion exceeds root depth [30]. Root depth is equal to the minimum water table level recorded during the preceding summer. Mortality can happen through anoxia if free surface elevation is constantly higher than bed elevation from July $1^{\text {st }}$ to September $1^{\text {st }}$. 


\subsection{Numerical simulation scenarios}

Numerical investigations were performed in a simplified gravel bed river reach, the characteristics of which are inspired from a reach of the Isère River presented on Figure 1. It consists of a $10 \mathrm{~km}$ long straight channel with a constant width of $112 \mathrm{~m}$, a constant longitudinal slope of 0.002 , and a uniform sediment diameter of $0.020 \mathrm{~m}$. The computational domain is discretized with triangular elements with typical sizes in the order of 5 to $7 \mathrm{~m}$. The initial topography is obtained by letting the bed freely develop a pattern of free migrating alternate bars with a constant, full-transporting water discharge of $200 \mathrm{~m}^{3} / \mathrm{s}$. Fully developed free bars have an average wavelength of $480 \mathrm{~m}$. Sediment feed is maintained at equilibrium at the upstream boundary.

Four simulation scenarios were investigated, consisting of 50 repetitions of a simplified yearly hydrogram presented on Figure 2, representing 50 years of vegetation evolution. For computation purposes, the calendar year relevant to vegetation development is accelerated as compared to the time of hydraulic and morphodynamic evolution: 1 year of vegetation evolution is simulated through 183 hours of hydraulic computations, which include a flood lasting 24 hours and 159 hours of low flows. During the recruitment months, hydrological conditions are favorable for vegetation colonization on bar tops, with a slow water stage decline followed by a stable low flow. Each year, a symmetrical triangular flood is modeled with a duration of 24 hours and a peak discharge $Q_{p}$ which is different for each scenario: for Scenario $1, Q_{p}=200 \mathrm{~m}^{3} / \mathrm{s}$; for Scenario $2, Q_{p}=400 \mathrm{~m}^{3} / \mathrm{s}$; for Scenario $3, Q_{p}=800 \mathrm{~m}^{3} / \mathrm{s}$; and Scenario 4 presents interannual variability: two consecutive years have a peak discharge $Q_{p}=200 \mathrm{~m}^{3} / \mathrm{s}$, and one in three years has a peak discharge $Q_{p}=800 \mathrm{~m}^{3} / \mathrm{s}$. The vegetation parameters used in this study are derived from field measurements of poplars and willows of 1 to 10 years [31]. For vegetation height, $G_{i n}=0.25 \mathrm{~m}$ and $F_{v}=2 \mathrm{~m} /$ year; for vegetation diameter, $G_{\text {in }}$ is $0.002 \mathrm{~m}$ and $F_{v}$ is $0.013 \mathrm{~m} /$ year (eq. 2). Stem density $m$ is $5 \mathrm{~m}^{-2}$.

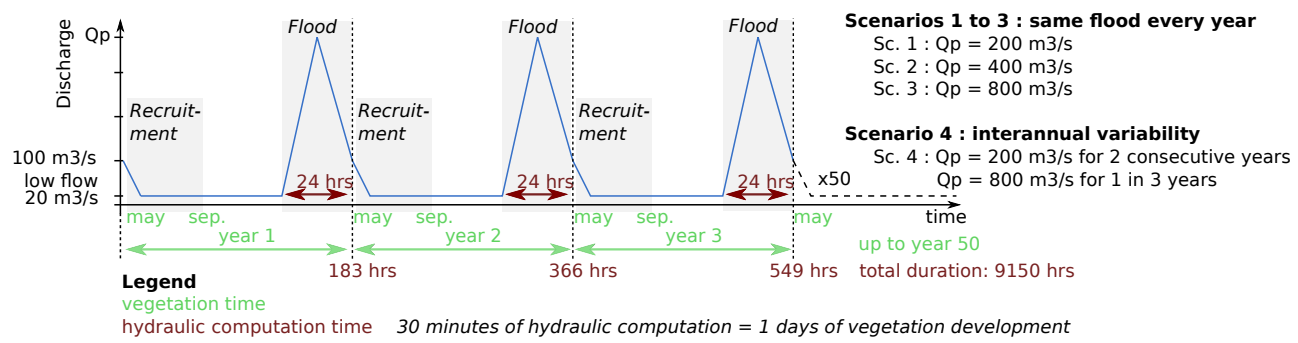

Figure 2. Simulated hydrological scenarios

\section{Results and discussion}

\subsection{General pattern of biomorphological evolution of the modeled reach}

The simulated reach presents similar evolution characteristics for all scenarios: a steady increase in vegetation cover strongly impacts the evolution of bar morphology, until a relatively stable equilibrium is reached after one to three decades. This trend can be observed on Figure 3, which presents the evolution of vegetation cover in all runs. At equilibrium, vegetation covers 25 to $30 \%$ of the reach, as compared to 35 to $45 \%$ for the Isere River [15].

Vegetation development on bars is concomitant to an increase in bar wavelength and a decrease in bar width. This can be observed on Figure 4, presenting the planform evolution 


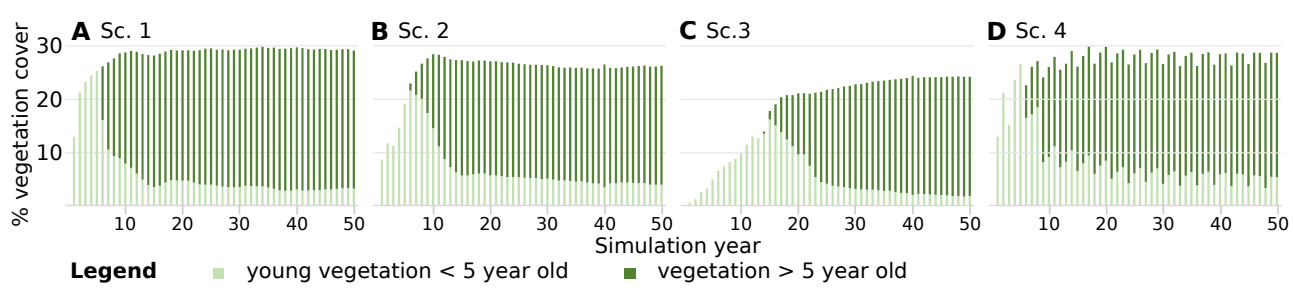

Figure 3. Yearly evolution of vegetation cover in the simulations: A. Scenario 1, B. Scenario 2, C. Scenario 3, and D. Scenario 4

of the reach for Scenarios 1 to 4, and on Table 1 showing the average equilibrium bar dimensions. Similar behavior can be observed in the Isère reach presented on Figure 1.A and B. In the simulations, vegetation development on bars is associated to a concentration of flow velocities and sediment transport intensity in the active channel, and to a complete stabilization of the bars over time (celerity is 0 ). Vegetalization as well as stabilization of bars have also been observed in the case of the Isere River [15]. At equilibrium, a slight morphodynamic activity takes place at the bar margins, allowing for the persistence of a fraction of young vegetation, as can be observed on Figure 3 and Table 1.

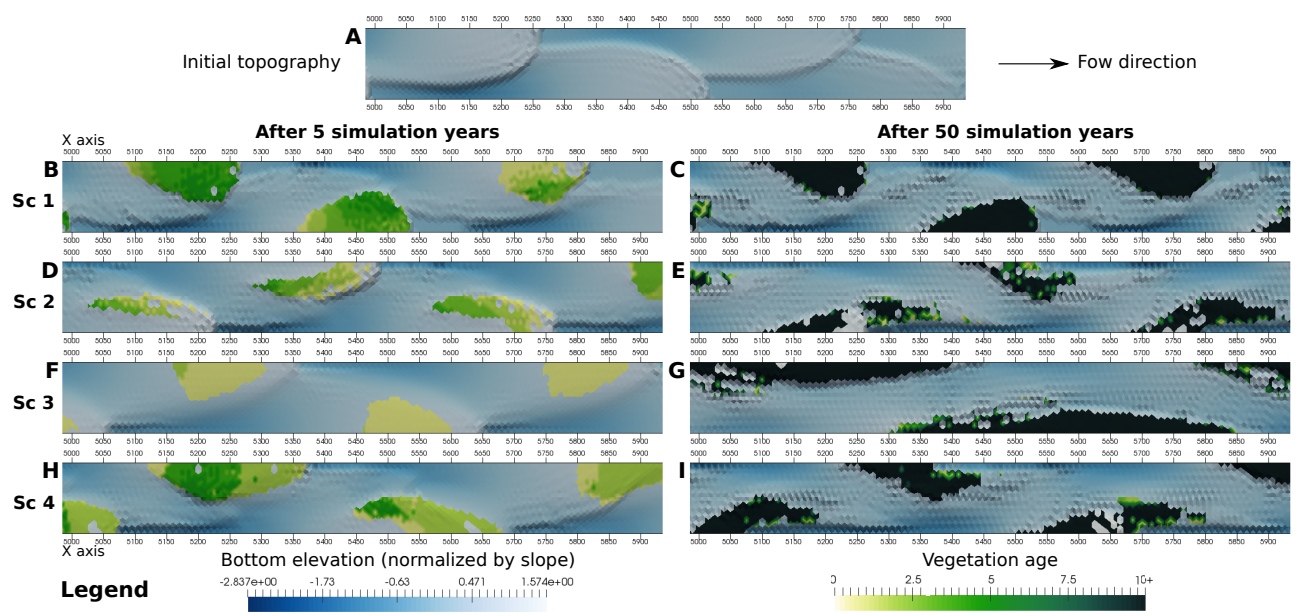

Figure 4. Planform evolution of bars for different scenarios, at distinct simulation stages: A. Initial topography, B. and C. Scenario 1, D. and E. Scenario 2, F. and G. Scenario 3, H. and I. Scenario 4, after 5 simulation years (B., D., F., and H.) and after 50 simulation years (C., E., F., and I.)

\subsection{Influence of flood discharge on transient state}

According to Figure 3, the duration of the transient state depends upon flood peak discharge. It lasts about 10 years in Scenario $1\left(Q_{p}=200 \mathrm{~m}^{3} / \mathrm{s}\right), 15$ to 20 years in Scenario $2\left(Q_{p}=\right.$ $\left.400 \mathrm{~m}^{3} / \mathrm{s}\right)$ and up to 20 to 30 years in Scenario $3\left(Q_{p}=800 \mathrm{~m}^{3} / \mathrm{s}\right)$. In Scenario 1 , bed mobility during floods is low even with no or little vegetation. As a result, vegetation mortality is very low, and equilibrium conditions are reached as soon as vegetation is fully developed. In contrast, in Scenario 3, almost all new vegetation is subject to mortality during floods during 
Table 1. Bar dimensions and vegetation cover at equilibrium

\begin{tabular}{lcccc}
\hline Scenario & $\begin{array}{c}\text { Mean } \\
\text { wavelength }(\mathrm{m})\end{array}$ & $\begin{array}{c}\text { Mean bar width } \\
(\mathrm{m})\end{array}$ & $\begin{array}{c}\text { \% Vegetation } \\
\text { cover at end of } \\
\text { simulation }\end{array}$ & $\begin{array}{c}\text { \% Vegetation } \\
\text { younger than } \\
\text { 5 years old }\end{array}$ \\
\hline Initial & $478 \pm 69$ & $90 \pm 7$ & & \\
Sc. 1 & $550 \pm 72$ & $55 \pm 7$ & 29 & 11 \\
Sc. 2 & $618 \pm 56$ & $46 \pm 9$ & 26 & 15 \\
Sc. 3 & $752 \pm 136$ & $36 \pm 10$ & 24 & 7 \\
Sc. 4 & $629 \pm 74$ & $49 \pm 10$ & 27 & $12-19$ \\
\hline
\end{tabular}

the first few simulation years, which is due to very high bed mobility. Enough vegetation survives to eventually stabilize the bar and facilitate further vegetation development, but the vegetalization process is longer. In Scenario 4 , where $Q_{p}$ alternates between $200 \mathrm{~m}^{3} / \mathrm{s}$ and $800 \mathrm{~m}^{3} / \mathrm{s}$ ( 1 in 3 years), the duration of the transient state is similar to that of Scenario 1 , suggesting that it is controlled by smaller, more frequent floods rather than larger, rarer floods.

Flood discharges and overall bed mobility also seem to determine the distribution of vegetation ages during the vegetalization process, as shown on Figure 4.B., D., F and H. In Scenario 1 with little bed mobility, older vegetation stands at the bar head (Figure 4.B). The presence of this vegetation triggers sediment deposition upstream, creating new surfaces available for vegetation colonization in subsequent years. This process allows progressive upstream bar growth. In contrast, in Scenario 2 and 3 where bed mobility is more important, older vegetation stands on the bar tail (Figure 4.D and F). In this case, bar migration continues through the first few years of vegetation colonization, so that the upstream ends of bars are eroded. The vegetation which has been able to survive acts as a shelter, allowing sediment deposion and development of new vegetation downstream of the vegetation patch. This process results in downstream bar growth. Both configurations can also be observed in real rivers: Figure 5.A shows a bar with older vegetation on its head, while Figure 5.B presents a bar with older vegetation on its tail.
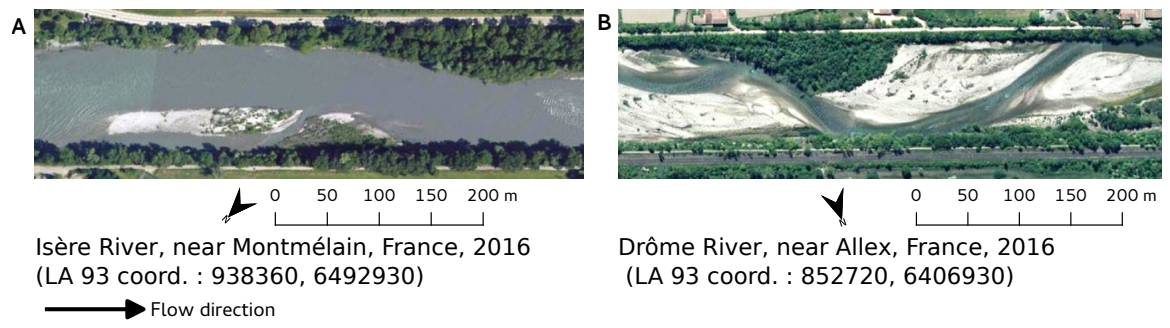

Figure 5. Exemples of bars with different vegetation distribution: A. Isère River, near Montmélian, older vegetation stands at the bar head, B. Drôme River, near Allex, older vegetation stands at the bar tail

\subsection{Influence of flood discharge on equilibrium state}

Flood discharges seem to impact vegetation cover. In Scenario 1, vegetation covers $29 \%$ of the channel area, in Scenario 2 it covers 26\%, and in Scenario 3, 24\%. This suggests that larger floods may lead to less overall vegetation cover, although the range of modeled vegetation covers is narrow $( \pm 5 \%)$ as compared to the range of modeled discharges (factor 
of 1 to 4). Moreover, higher flood discharges lead to both longer and thinner bars (Figure 4 and Table 1). Indeed, in order to reach equilibrium sediment transport capacity, larger floods require a greater active width, limiting the width which can be occupied by vegetation. In scenarios where mobility is more important, bar elongation processes are more efficient.

The variability of equilibrium vegetation cover is related to the interannual flood variability. In Scenario 1, 2, and 3, for which the same flood occurs every year, equilibrium vegetation cover is very stable (Figure 3). In Scenario 4, a more important flood every three years leads to a reduction in vegetation cover, which increases back on the two following years; vegetation cover reaches a dynamic equilibrium with more variability.

The link between flood discharges and the presence of young vegetation in the channel at equilibrium is not straighforward. The presence of young vegetation during equilibrium is an indication of the intensity of bedform turnover. The fraction of young vegetation is most variable in Scenario 4, varying from 12 to $20 \%$ of total vegetation (Table 1). Larger floods lead to mortality of young vegetation, but also to the creation of new surfaces which can be colonized by new vegetation. Yet, despite the absence of interannual flood variability, the fraction of young vegetation at equilibrium in Scenario 2 is in the same range (15\%, Table 1), indicating bedform turnover also in this configuration. The fraction of young vegetation is lowest for Scenario 3 (7\%, Table 1) which has the greatest flood peak discharge.

\section{Conclusions and perspectives}

The module for vegetation dynamics implemented in the Telemac-Mascaret modeling system has shown qualitatively satisfactory results, as it is able to reproduce a range of realistic configurations of vegetated alternate bars. Modeled equilibrium stages have been more stable than we expected, especially for higher discharges. This may result from an overestimation of vegetation impact on the flow field or from a simplistic representation of bank erosion processes, but can also be attributed to the simplicity of considered hydrological scenarios.

This study has shown that flood regime influences the time it takes for vegetation to colonize river bars, as well as vegetation age distribution on these bars and equilibrium bar dimensions. Larger floods seem to lead to less vegetation cover in the channel, yet they do not necessarily maintain a greater variety of vegetation ages than intermediate flood discharges. Even in the case of important sediment transport, the active channel can be almost disconnected from almost static vegetated bars. In contrast, flood discharge variability seems to favor bedform and vegetation turnover. This phenomenon has also been observed in other studies [6, 32], implying that vegetation management through flow manipulation should be planned at decadal timescales in order to allow for interannual flood variability.

Future works will aim at deepening our understanding of the influence of flow variability on vegetation dynamics, by considering greater interanual variability of flood peak discharges as well as summer low flow variability, which can influence colonization success. Lasting intermediate flows are likely to be another important driver of vegetation dynamics which can be explored with this model.

\section{References}

[1] G.P. Williams, The case of the shrinking channels: the North Platte and Platte Rivers in Nebraska, Vol. 781 (Department of the Interior, Geological Survey, 1978)

[2] F. Comiti, M. Da Canal, N. Surian, L. Mao, L. Picco, M.A. Lenzi, Geomorphology 125, $147(2011)$

[3] F. Liébault, H. Piégay, Earth Surface Processes and Landforms 27, 425 (2002) 
[4] J.V. Ward, K. Tockner, D.B. Arscott, C. Claret, Freshwater Biology 47, 517 (2002)

[5] G.M. Kondolf, P.R. Wilcock, Water Resources Research 32, 2589 (1996)

[6] F.M. Hughes, S.B. Rood, Environmental Management 32, 12 (2003)

[7] M. Colombini, G. Seminara, M. Tubino, Journal of Fluid Mechanics 181, 213 (1987)

[8] A. Crosato, E. Mosselman, Water Resources Research 45 (2009)

[9] S. Lanzoni, Water Resources Research 36, 3337 (2000)

[10] A. Crosato, F.B. Desta, J. Cornelisse, F. Schuurman, W.S. Uijttewaal, Water Resources Research 48 (2012)

[11] F. Cordier, P. Tassi, N. Claude, A. Crosato, S. Rodrigues, D. Pham van Bang, Water Resources Research (under review)

[12] L. Adami, W. Bertoldi, G. Zolezzi, Water Resources Research 52, 8938 (2016)

[13] M. Jaballah, B. Camenen, L. Pénard, A. Paquier, Advances in Water Resources 81, 103 (2015)

[14] W. Bertoldi, A. Siviglia, S. Tettamanti, M. Toffolon, D. Vetsch, S. Francalanci, Geophysical Research Letters 41, 7167 (2014)

[15] A. Serlet, A. Gurnell, G. Zolezzi, G. Wharton, P. Belleudy, C. Jourdain, Earth Surface Processes and Landforms 48 (2018)

[16] D. Corenblit, E. Tabacchi, J. Steiger, A.M. Gurnell, Earth-Science Reviews 84, 56 (2007)

[17] A. Gurnell, Earth Surface Processes and Landforms 39, 4 (2014)

[18] A. Crosato, M.S. Saleh, Earth Surface Processes and Landforms 36, 711 (2011)

[19] A.P. Nicholas, Earth Surface Processes and Landforms 38, 1187 (2013)

[20] M. van Oorschot, M. Kleinhans, G. Geerling, H. Middelkoop, Earth Surface Processes and Landforms 41, 791 (2016)

[21] D. Wang, P. Tassi, 21st TELEMAC-MASCARET User Conference 2014 pp. 239-247 (2014)

[22] E. Meyer-Peter, R. Müller, IAHSR 2nd meeting, Stockholm, appendix 2 (1948)

[23] C. Villaret, J.M. Hervouet, R. Kopmann, U. Merkel, A.G. Davies, Computers \& Geosciences 53, 105 (2013)

[24] K. El Kadi Abderrezzak, A.D. Moran, P. Tassi, R. Ata, J.M. Hervouet, Advances in Water Resources 93, 75 (2016)

[25] B.M. Stone, H.T. Shen, Journal of hydraulic engineering 128, 500 (2002)

[26] N. Claude, G. Antoine, R. Yassine, V. Verschoren, C. Schwarz, S. Temmerman, C. Jourdain, 22nd TELEMAC-MASCARET User Conference 2015 pp. 213-214 (2015)

[27] J.M. Mahoney, S.B. Rood, Wetlands 18, 634 (1998)

[28] W.C. Johnson, Hydrological Processes 14, 3051 (2000)

[29] L. Kui, J.C. Stella, Forest Ecology and Management 366, 32 (2016)

[30] S. Bywater-Reyes, A.C. Wilcox, J.C. Stella, A.F. Lightbody, Water Resources Research 51, 9190 (2015)

[31] C. Jourdain, PhD Thesis, Université Grenoble-Alpes (2017)

[32] R. Rivaes, I. Boavida, J.M. Santos, A.N. Pinheiro, M.T. Ferreira, Hydrology \& Earth System Sciences Discussions 12 (2015) 